\title{
ACESSIBILIDADE COMO FERRAMENTE DE INCLUSÃO SOCIAL: PROPOSTA DE ADEQUAÇÃO DA ACESSIBILIDADE PARA CONCESSIONÁRIA DE VEÍCULOS.
}

\author{
LUCENA, Mariana (1); \\ SANTIAGO, Larissa (2) \\ (1) Centro Universitário de João Pessoa - UNIPÊ, Mestre em Arquitetura e \\ Urbanismo e-mail:marianacmlucena@gmail.com \\ (2) Centro Universitário de João Pessoa - UNIPÊ, Graduanda em Arquitetura e \\ Urbanismo e-mail:larissacsantiago96@gmail.com
}

\begin{abstract}
RESUMO
Este artigo tem como objetivo apresentar o processo de adequação para pessoas em cadeira de rodas para concessionária AutoClub Honda em Campina Grande-PB, obtenção da certificação Honda Conduz, que propõe inclusão dos usuários, a partir do cumprimento das NBR 9050/2015. Tomou-se como base para análise do local o método desenvolvido para o programa de acessibilidade às pessoas com deficiência de Santa Catarina, a partir da definição dos conceitos básicos para a compreensão do problema e formulados os componentes de acessibilidade espacial que orientam a certificação Honda Conduz. A partir da análise in loco concluiu-se que a Honda Campina Grande, por não cumprir totalmente os requisitos da NBR 9050/2015, passou por adequações de nível fácil e com pequenas intervenções.
\end{abstract}

Palavras chave: acessibilidade; inclusão; adaptação.

\begin{abstract}
This article aims to present the suitability process for people in wheelchairs for AutoClub Honda concessionaire in Campina Grande-PB, obtaining the Honda Conduz certification, which proposes inclusion of users, as of compliance with NBR 9050/2015. The method developed for the accessibility program for people with disabilities in Santa Catarina was taken as a basis for the analysis of the place, from the definition of the basic concepts to the understanding of the problem and formulated the components of space accessibility that guide the Honda conduction certification. Based on the on-site analysis, it was concluded that Honda Campina Grande, for not fully complying with the requirements of NBR 9050/2015, underwent easy level adjustments and with small interventions.
\end{abstract}

Keywords: accessibility; inclusion; adaptation.

\section{INTRODUÇÃO}

Espaços públicos são de grande importância para a sociedade e seus usuários, é neles que se desenvolvem as relações sociais capazes de promover integração entre as mais variadas classes sociais. De acordo com Netto (2006), o espaço não é um pano de fundo para o comportamento social - ele, em si, gera o comportamento social. Portanto, é imprescindível um grau de mobilidade que englobe toda a população e seus grupos específicos. 


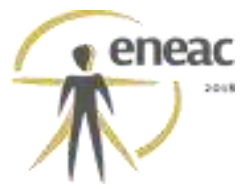

Segundo Netto (2006), nos dias atuais é possível se ter a sensação de que os espaços não promovem mais o ideal moderno de universalidade, ao contrário, o que deveria ser utilizado e desfrutado por todos, se torna restrito devido a presença de barreiras físicas que impedem a livre circulação e a utilização correta do espaço, fazendo assim, com que o espaço não cumpra o seu sentindo em existir.

Para Ferreira et al. (2007), acessibilidade é uma situação de utilização de ambientes públicos e privados, em condição de conforto e segurança, através de dispositivos, produtos, serviços e sistemas de informação, destinados aos diversos grupos de usuários destes ambientes: crianças, idosos, gestantes, deficientes e população adulta em geral. O espaço deve permitir o acesso, através do uso igualitário às pessoas com diversas dificuldades, evitando segregar, ou até mesmo diferenciar qualquer indivíduo, para que esse realize suas atividades com autonomia, segurança, agilidade, liberdade e igualdade.

A igualdade é um direito fundamental constitucionalmente, como também a assistência social, tendo como um dos objetivos a integração à vida comunitária para pessoas em cadeira de rodas (P.C.R). Para assegura os direitos de todos os cidadãos portadores de deficiência, em 2015, foi promulgado o Estatuto da Pessoa com Deficiência que assegura a inclusão e acessibilidade em vários aspectos da sociedade.

A acessibilidade e a forma como ela é posta, em suas diversas vertentes, traz o poder de inclusão social, por parte daqueles que de alguma forma se sentem, e como consequência da falta de acessibilidade acabam se tornando, incapazes de viver normalmente, com a sua liberdade e independência.

O conceito de acessibilidade vem mudando nos dias de hoje, a pessoa com deficiência, não é mais vistas como incapaz. De acordo, com Kaufman- Scarborough (1998), investimentos em acessibilidade de loja, atendimento a clientes com deficiência representam decisões potencialmente efetivas para distinguir a empresa de seus concorrentes perante os públicos interno e externo, pelo fato da acessibilidade passar a ser mais do que uma adaptação em determinado local, mas a igualdade, quando se diz respeito a mesmas oportunidades em todas as áreas da vida.

Quando um indivíduo com deficiência adentra um ambiente de varejo, seu maior desejo é ser visto como um consumidor, não como um problema a ser resolvido e depois removido da loja. (Baker, Holland, \& Kaufman-Scarborough, 2007)

Um ambiente que não oferece condições adequadas, desde a arquitetura, à forma de tratamento, apresenta uma situação desfavorável ao portador de deficiência, tendo em vista que dificulta suas ações, o excluindo da sociedade, do convívio (NBR 9050/2015). De acordo com Dischinger, et al. (2012), é fundamental promover mudanças no ambiente físico para atingir melhores condições de acessibilidade espacial e permitir a todas as pessoas a realização de atividades desejadas, de forma que possam estar incluídas no espaço, ou seja, partir do momento em que todos podem se utilizar livremente dos mesmos bens e serviços sem que haja dificuldade, ou algum tipo de constrangimento (FARIA, et al, 2013).

Um fator que é de grande importância e que ajuda na compreensão da acessibilidade gerando a inclusão, é a informação. Quando a sociedade passa a se informar e ter acesso as necessidades apresentas pelo portador de deficiência, bem como da sua capacidade de realizar seus desejos e ações como todos, há uma maior conscientização, eliminando o preconceito e o entendimento que para que haja inclusão, é necessário que as pessoas tenham o mesmo acesso ao que é oferecido. 


\section{OBJETIVOS}

\subsection{Objetivo Geral}

Desenvolver proposta de adequação para pessoas em cadeira de rodas, de acordo com a NBR 9050/2015, na concessionária Autoclub Honda em Campina Grande, PB.

\subsection{Objetivos Específicos}

- Avaliar a acessibilidade para pessoas em cadeira de rodas;

- Identificar as inadequações a NBR 9050/2015;

- Classificar o nível de adequação para atender as exigências da NBR 9050/2015.

\section{METODOLOGIA}

Primeiramente foram realizadas pesquisas bibliográficas, em livros, artigos científicos, dissertações e teses, com o objetivo de obter o conhecimento e armazenar informações.

Posteriormente foram feitas pesquisas de campo, onde foram definidos os conceitos básicos para a compreensão do problema e formulados os componentes de acessibilidade espacial que orientam a certificação Honda Conduz: vaga demarcada, acessos e banheiro adaptado.

Para análise tomou-se como base para o processo de análise do local o método desenvolvido por DISCHINGER, et al. (2012), para o Programa de Acessibilidade às Pessoas com Deficiência ou Mobilidade Reduzida nas Especificações de Uso do Ministério Publico de Santa Catarina, juntamente com a utilização da NBR 9050/2015.

\section{DISCUSSÃO E RESULTADOS}

A AutoClub Honda, revendedor autorizado Honda para o Estado da Paraíba desde 1999, atuando no mercado automobilístico. A unidade AutoClub Honda que se apresenta como objeto de estudo deste artigo, se encontra na rua Otacílio Nepomuceno, no bairro Catolé, localizado na cidade de Campina Grande-PB. Inaugurada no ano de 2016, conta com estrutura física de 4.000,00 $\mathrm{m}^{2}$, composta por área para estacionamento de veículos, pátio veículos, setor de vendas, setor administrativo, banheiros sociais, área de espera e setor de oficina/manutenção.

O processo se iniciou pela necessidade do atendimento aos parâmetros do programa de Certificação Honda Conduz, que tem como finalidade avaliar as concessionárias e pontos de venda estão aptos a atenderem ao portador de deficiência, com o intuito de oferecer um atendimento diferenciando, facilitando a aquisição de veículos com isenção de impostos para pessoas em cadeira de rodas (P.C.R), tendo como prerrogativa que o cliente tenha autonomia na utilização do espaço de acordo com a NBR 9050/2015.

\subsection{Vaga Demarcada}

De acordo com a NBR 9050 (2015), nos estacionamentos externos ou internos das edificações de uso público ou coletivo, deve haver vagas para P.C.R, sendo os percentuais da quantidade determinados pela legislação específica do município. Para a cidade de Campina Grande, o Código de Obras (2013) determina que 1\% do número total de vagas seja destinado a pessoas em cadeira de rodas. O estabelecimento avaliado dispõe de um total de 11 (onze) vagas para automóveis, sendo 01 (uma) 


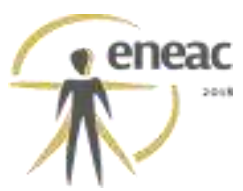

destinada à pessoa em cadeira de rodas, localizada próxima a entrada principal da edificação, posicionada de forma que não há circulação entre veículos, possui piso regular e estável, atende a determinação de possuir circulação lateral para pedestres com largura de $1,20 \mathrm{~m}$. Quanto à sinalização a mesma dispõe apenas de indicação horizontal, não estando apenas no item sinalização vertical em conformidade com a NBR 9050 (2015) (Figura 01).

Figura 01 - Foto vaga reservada.

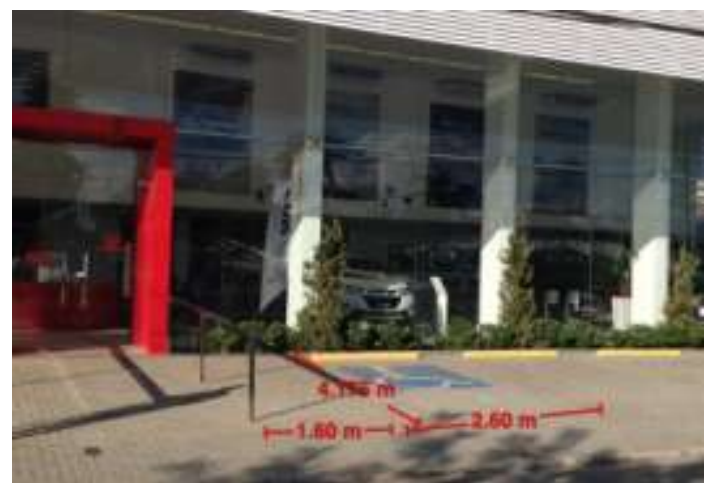

Fonte: Acervo pessoal, 2017

Tabela 1 - Quadro resumo inadequações vaga demarcada

\begin{tabular}{c|l}
\hline Inadequações & \multicolumn{2}{c}{ Nível de Adequação } \\
\hline Não possui sinalização vertical & \multicolumn{2}{|l}{} \\
\hline LEGENDA & Fácil adequação \\
\hline & Adequação com intervenções \\
\hline
\end{tabular}

Fonte: Produzido por LUCENA, 2017.

\subsection{Acessos}

Nas edificações e equipamentos urbanos, a entrada principal ou a entrada de acesso do maior número de pessoas, tem a obrigatoriedade de atender a todas as condições de acessibilidade (NBR 9050, 2015).

Acessibilidade é a possibilidade e condição de alcance, percepção e entendimento para utilização, com segurança e autonomia, de espaços e mobiliáriospor pessoa com deficiência (...) (NBR 9050, 2015).

Pode-se observar que a entrada principal da edificação possui rampa de acesso com inclinação de 3,4\% (comprimento de $4,50 \mathrm{~m}$ e desnível de $0,15 \mathrm{~m}$ ) e largura livre para circulação de 2,30. Apresenta corrimãos instalados em ambos os lados com altura de $0,90 \mathrm{~m}$ (medido da face superior até o piso) com seção retangular medindo $0,10 \times 0,05 \mathrm{~m}$. Os corrimãos dispõem de prolongamento de $0,19 \mathrm{~m}$ antes do início da rampa (Figura 02). As arestas nas extremidades são vivas, oferecendo risco de acidentes.

A partir das recomendações da NBR 9050 (2015) é possível concluir que a rampa de acesso está adequada aos padrões exigidos, possuindo inclinação inferior a 5\% e largura superior ao mínimo admissível - 1,20m. Os corrimãos atendem a norma vigente no que diz respeito a instalação em ambos os lados, no entanto não estão instalados nas alturas exigidas a $0,92 \mathrm{~m}$ e $0,70 \mathrm{~m}$ medidos da face superior ao piso; não possuem 


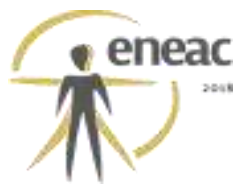

prolongamento mínimo de $0,30 \mathrm{~m}$ antes do início e após o término da rampa e o formato da seção não atende ao requisito de ter seção circular com diâmetro entre $0,30 \mathrm{~m}$ e 0,45 m ou seção elíptica, desde que a dimensão maior seja de $0,45 \mathrm{~m}$ e a menor de $0,30 \mathrm{~m}$.

Figura 02 - Medidas corrimãos, rampa de acesso principal AutoClub Honda Campina Grande

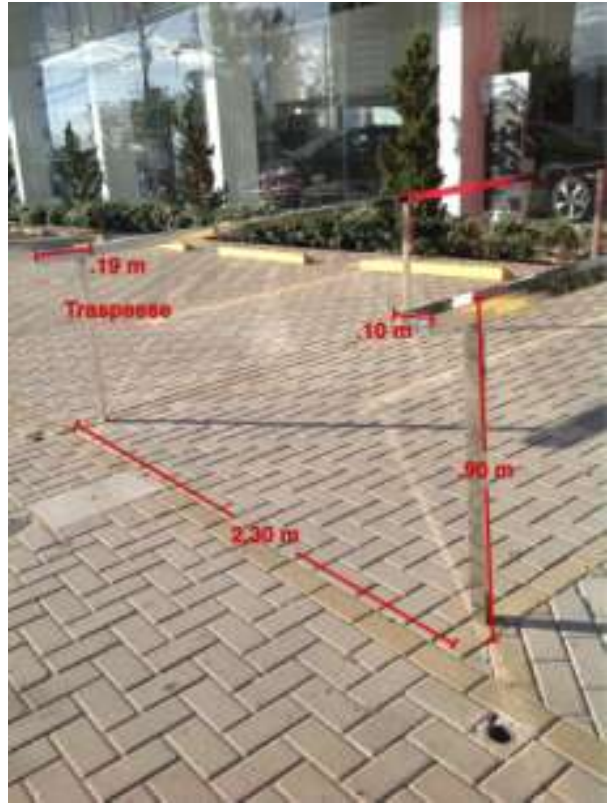

Fonte: Acervo pessoal, 2017

A porta da entrada principal é de vidro e possui vão de 2,00m (Figura 03). Não há desnível entre o piso externo e interno e a edificação e não possui sinalização visual de forma contínua, visando permitir a fácil identificação visual da barreira física. O acesso a recepção e oficina têm porta em vidro, com sinalização visual de forma contínua e vão livre de $0,90 \mathrm{~m}$, não havendo desnível entre o piso externo e interno (Figura 04). Com isto averiguamos que no que diz respeito a dimensão e inexistência de desnível os acessos estão de acordo com a NBR 9050 (2015), entretanto, no quesito identificação visual, a concessionária não atende a norma para as portas e paredes envidraçadas.

Figura 03 e 04: Entrada principal e entrada recepção oficina, AutoClub Honda Campina Grande
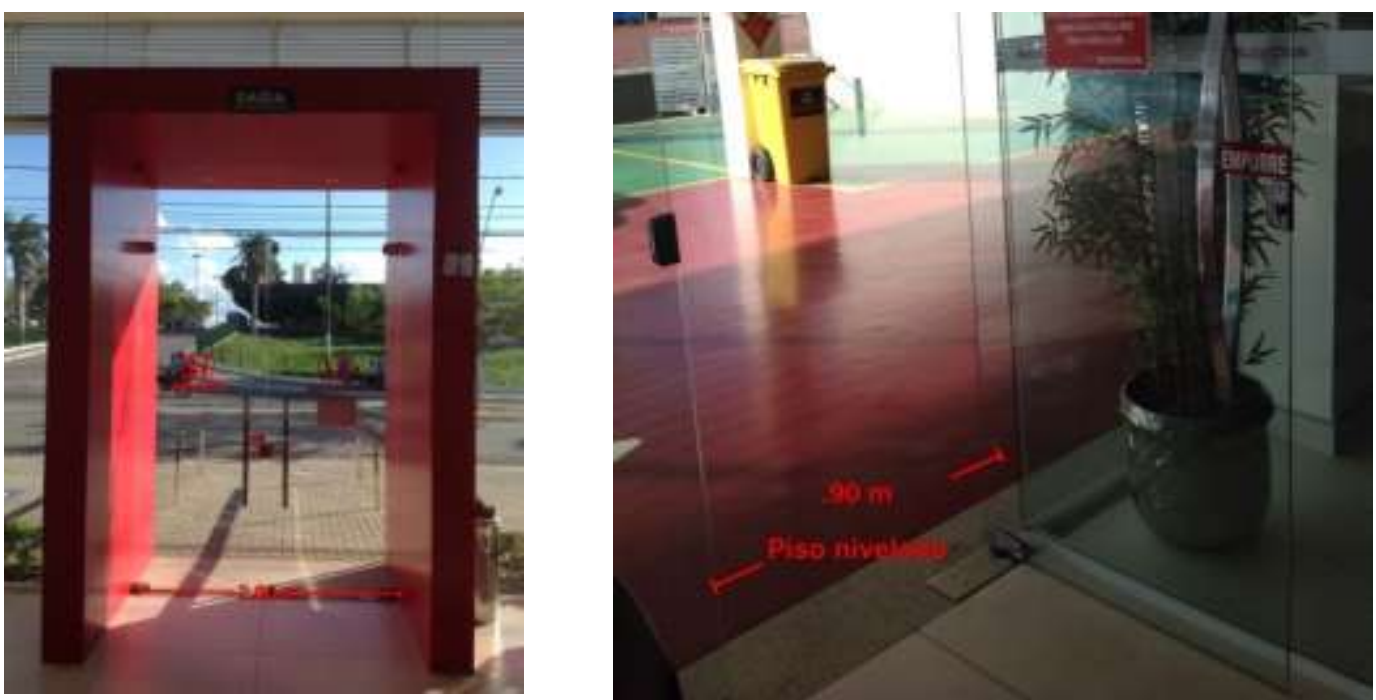

Fonte: Acervo pessoal, 2017 
Tabela 2 - Quadro resumo inadequações acessos

\begin{tabular}{l|l}
\hline \multicolumn{1}{c|}{ Inadequações } & \multicolumn{2}{l}{ Nível de Adequação } \\
\hline $\begin{array}{l}\text { Corrimão não atende a recomendação da altura de instalação a } \\
0,70 \mathrm{~m} \text { do piso }\end{array}$ \\
\hline $\begin{array}{l}\text { Formato e dimensão da seção não atendem ao requisito de ter } \\
\text { seção circular ou elíptica com dimensão entre 0,030m e 0,045m. }\end{array}$ \\
\hline $\begin{array}{l}\text { Ausência de identificação visual contínua da barreira física na } \\
\text { porta entrada principal. }\end{array}$ & Fácil adequação \\
\hline & Adequação com intervenções \\
\hline
\end{tabular}

Fonte: Produzido por LUCENA, 2017

\subsection{Banheiro Adaptado}

Os banheiros acessíveis devem obedecer aos parâmetros da NBR 9050 (2015) quanto a áreas mínimas de circulação, de transferência e de aproximação, alcance manual, empunhadura e ângulo visual, bem como posicionamento e características das peças, acessórios barras de apoio, comandos e características de pisos e desnível.

A AutoClub Honda Campina Grande dispõe de 01 (um) banheiro acessível unissex, identificado com o símbolo internacional de acesso afixado em local visível ao público, próximo a circulação principal (setor de vendas, recepção oficina e sala de espera). A porta de acesso ao banheiro possui vão livre de $0,90 \mathrm{~m}$,com abertura para fora do banheiro e maçaneta do tipo alavanca, instalada a 1,06m do piso assentado (Figura 05).

\section{Figura 05 - Banheiro Acessível AutoClub Honda Campina Grande}

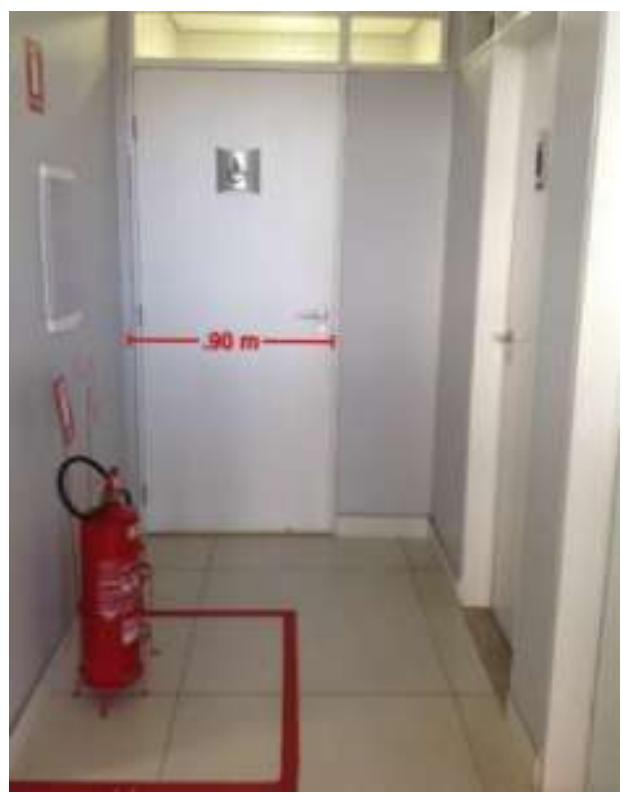

Fonte: Acervo pessoal, 2017 
O banheiro possui dimensão de 1,50m x 1,65m dotados de bacia sanitária com altura final de 0,46m (Figura 06); Bancada de dimensões 0,55m x 0,50m (Figura 07) com altura final $0,77 \mathrm{~m}$ e altura frontal livre na superfície inferior de $0,57 \mathrm{~m}$; Barras de apoio circular com diâmetro de $0,04 \mathrm{~m}$, posicionadas horizontalmente ao eixo da bacia sanitária e com comprimento de $0,85 \mathrm{~m}$ e altura de instalação de $0,92 \mathrm{~m}$ (lateral e fundo), com distância de $0,11 \mathrm{~m}$ do eixo da barra em relação a base da caixa acoplada da bacia sanitária. No que diz respeito à área de transferência lateral há uma distância de $0,92 \mathrm{~m}$ entre a parede e bacia sanitária assegurando assim as medidas corretas que possibilitam a transferência lateral.

Figura 06 e 07 - Banheiro Acessível AutoClub Honda Campina Grande

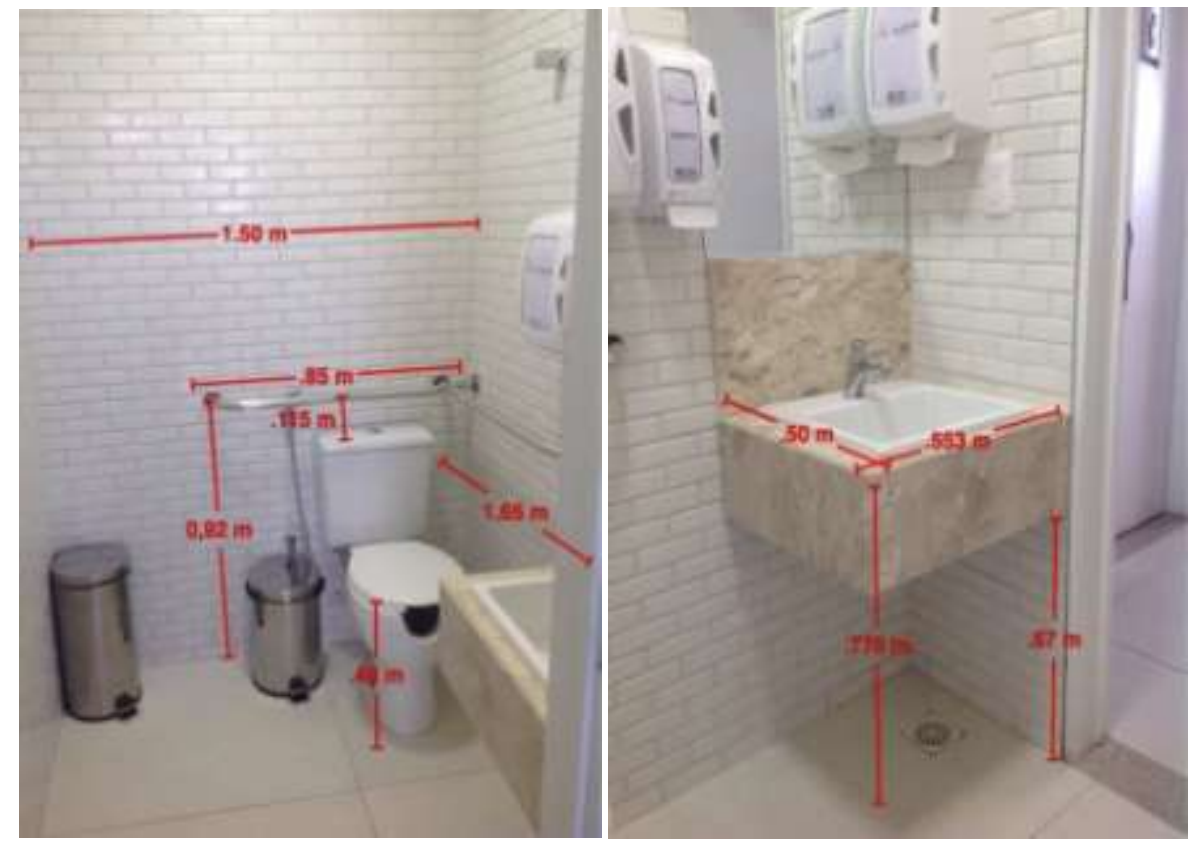

Fonte: Acervo pessoal, 2017

Diante do exposto constata-se que o banheiro acessível da AutoClub Honda Campina Grande está adequado a NBR 9050 (2015) quanto identificação do símbolo internacional, quanto as dimensões e sistema de abertura da porta, bem como a possibilidade de alcance manual para acionamento da válvula sanitária, da torneira e dos trincos. Os espelhos e uso dos acessórios (papeleira) não estão adequados a altura máxima de 0,90 e 1,20 (respectivamente). No que se refere às dimensões internas, se adequam as recomendações da norma vigente, possibilitando que seja feito o giro de $120^{\circ}$, barras de apoio posicionadas horizontalmente (lateral e fundo). No entanto foi verificado a ausência da barra reta (vertical), que deve ser instalada acima da barra horizontal de forma a garantir maior segurança na transferência lateral. A altura de instalação das barras de apoio não se adequam a altura máxima de $0,89 \mathrm{~m}$ exigida pela NBR 9050 (2015). No que se refere à utilização do lavatório, o mesmo possui altura final e área para aproximação da cadeira de rodas adequada a NBR 9050 (2015), porém a altura livre abaixo da bancada não possibilita o encaixe da pessoa em cadeiras de rodas por não atender a dimensão mínima de $0,65 \mathrm{~m}$. Observou-se a inexistências de barras de apoio nos lavatórios. 
Tabela 3 - Quadro resumo inadequações banheiro acessível

\begin{tabular}{|c|c|}
\hline Inadequações & Nível de Adequação \\
\hline \multicolumn{2}{|l|}{ Altura barras de apoio superior a $0,89 \mathrm{~m}$} \\
\hline \multicolumn{2}{|l|}{ Barra de apoio vertical } \\
\hline \multicolumn{2}{|l|}{ Ausência barras de apoio lavatório } \\
\hline \multicolumn{2}{|l|}{$\begin{array}{l}\text { Altura livre para aproximação da cadeira de rodas } \\
\text { inferior a } 0,65\end{array}$} \\
\hline \multicolumn{2}{|l|}{ Altura acessórios superior a 1,20m } \\
\hline \multicolumn{2}{|l|}{ Altura mínima base espelho superior a $0,90 \mathrm{~m}$} \\
\hline \multirow{2}{*}{ LEGENDA } & Fácil adequação \\
\hline & Adequação com pequenas intervenções \\
\hline
\end{tabular}

Fonte: Produzido por LUCENA, 2017

Mediante o exposto pode-se concluir que a AutoClub Honda BR 23, não cumpre em sua totalidade as exigências da NBR 9050 (2015) e o Decreto Federal no 5296/2004, necessitando assim de alterações com nível de adequação fácil (instalação de barras, adesivos, identificação visual, etc) e com pequenas intervenções.

\section{PROPOSTA DE ADEQUAÇÃO}

Para que a concessionária pudesse obter o Certificado Honda Conduz foram necessárias que todas as inadequações apontadas cumprissem em sua totalidade as exigências da NBR 9050/2015. Como já apresentado anteriormente, os três requisitos abordados no Certificado Honda Conduz, consistiu na análise da vaga demarcada, acessos e banheiros.

$\mathrm{Na}$ proposta foram, primeiramente, solicitadas as alterações de fácil adequação que consistiram na instalação da sinalização vertical com a identificação do símbolo internacional de acesso na vaga demarcada (Figura 08); Instalação de adesivo com a logo da loja, como identificação visual contínua da barreira física na porta entrada principal há uma altura entre 1,30m e 1,40m do piso acabado (Figura 09); No banheiro foram solicitadas a instalação de barras de apoio vertical instaladas à $0,90 \mathrm{~m}$ do piso e $0,85 \mathrm{~m}$ da parede adjacente, com $0,70 \mathrm{~m}$ de comprimento (para bacia sanitária) e $0,90 \mathrm{~m}$ do piso e $0,40 \mathrm{~m}$ da parede adjacente, com 0,40m de comprimento; e por fim foram ajustadas as alturas dos acessórios para 1,20m do piso acabado conforme a NBR 9050 (2015)(Figura 10).

Figura 08 e 09 - Vaga Demarcada Adaptada e Acesso principal com adesivo identificação visual contínua da barreira física, AutoClub Honda Campina Grande

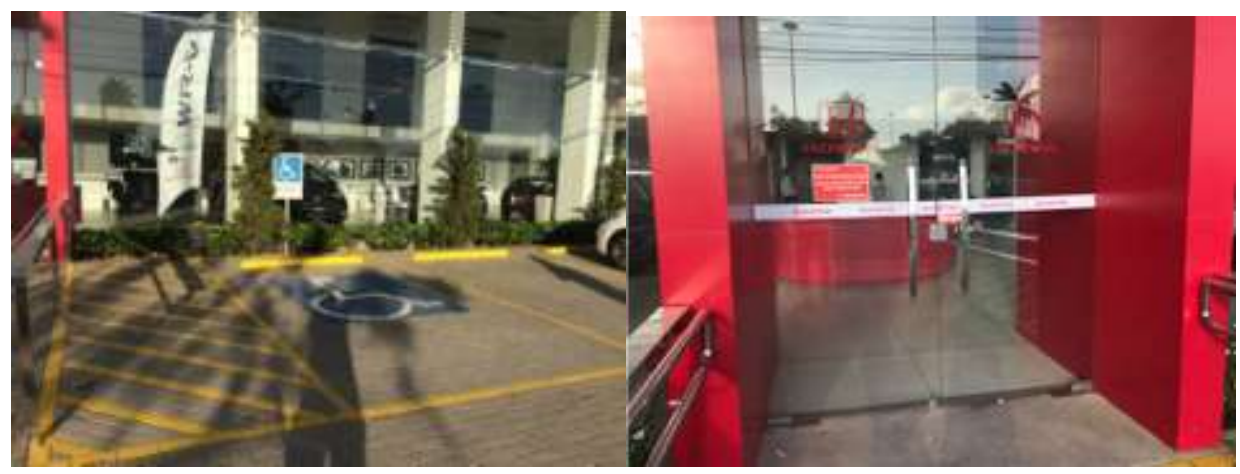

Fonte: Acervo pessoal, 2017 


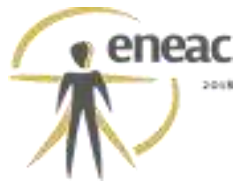

Figura 10 - Dimensões barras verticais e altura dos acessórios banheiro adaptado, AutoClub Honda Campina Grande
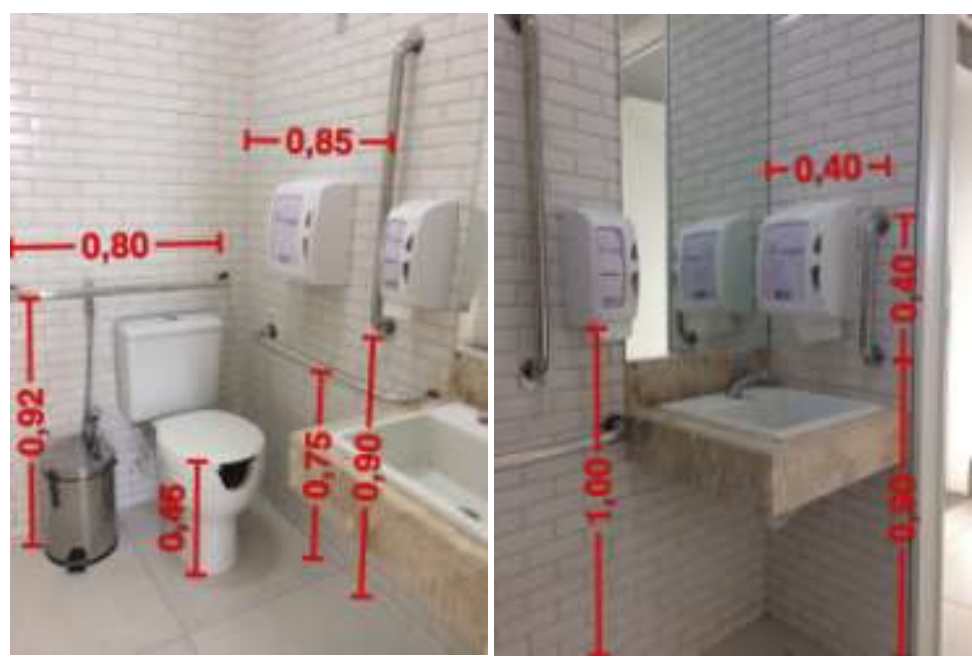

Fonte: Acervo pessoal, 2017

Posteriormente foi desenvolvido um projeto executivo, detalhado, com as respectivas medidas e especificações técnicas necessárias para que as adequações com pequenas intervenções estivem de acordo com a NBR 9050 (2015) (Figura 11). Conforme mencionado na etapa de análise os corrimãos do acesso principal não atendiam a recomendação da altura de instalação a $0,70 \mathrm{~m}$ do piso acabado, bem como o formato e dimensão da seção, que deveriam ser circular ou elíptica medindo entre $0,030 \mathrm{~m}$ e 0,045m de diâmetro. Assim, foram instalados corrimãos em ambos os lados, em aço inox polido, com diâmetro de $4 \mathrm{~cm}$, distantes $0,92 \mathrm{~m}$ e $0,70 \mathrm{~m}$ do piso e prolongamento com bordas arredondadas no início da rampa de 0,30cm (Figura 12).

Figura 11 - Projeto Executivo: Corrimão acesso principal, Autoclub Honda Campina Grande - PB

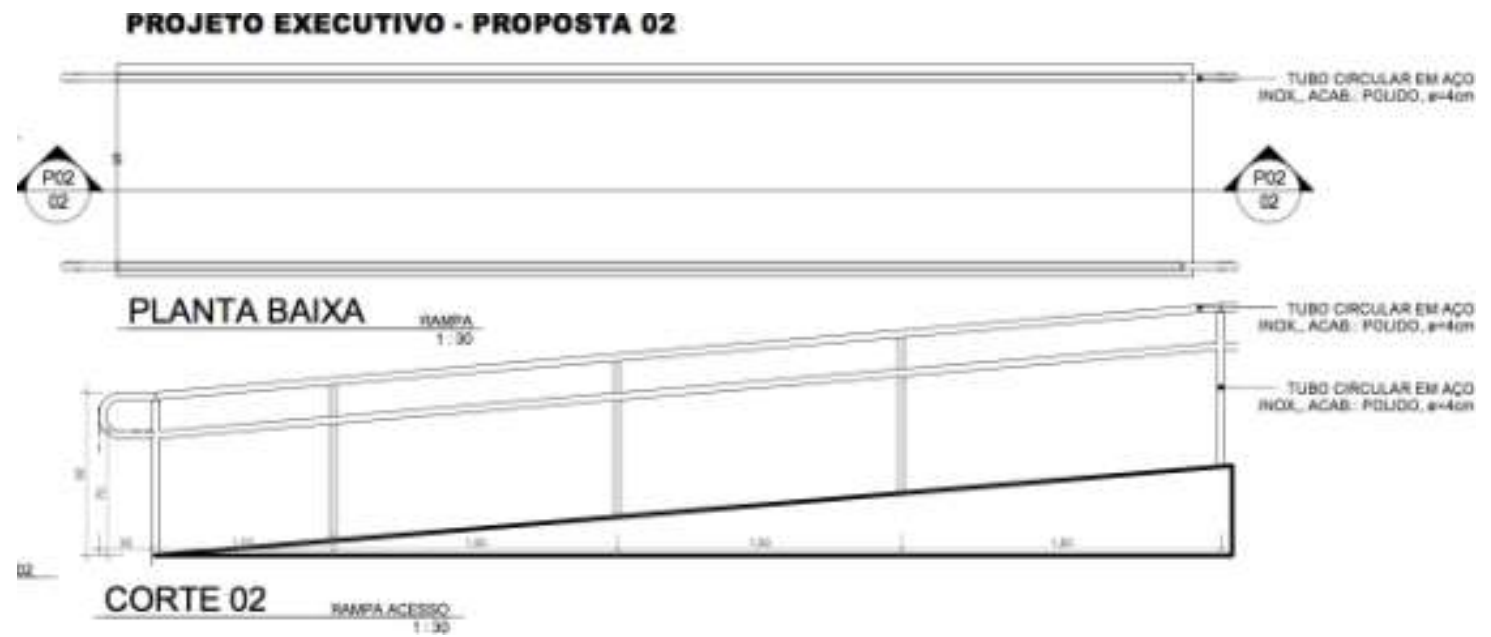

Fonte: LUCENA, 2017 


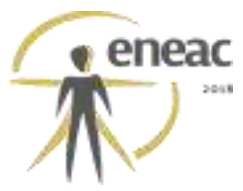

Figura 12 - Corrimãos Adaptados AutoClub Honda Campina Grande

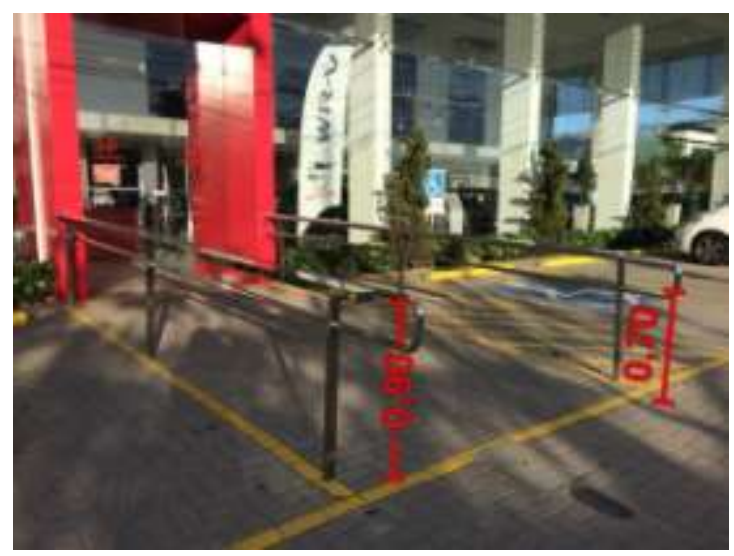

Fonte: Acervo pessoal, 2017

No que diz respeitos aos banheiros a barra de apoio lateral a bacia sanitária foi reinstalada a $0,75 \mathrm{~m}$ do piso e a $0,23 \mathrm{~m}$ da parede perpendicular (Figura 13). Para que fosse possível a aproximação da cadeira de rodas do lavatório foi necessária redução de $8 \mathrm{~cm}$ da testeira frontal, permitindo assim a altura livre de aproximação de $0,65 \mathrm{~m}$, bem como, a redução $21 \mathrm{~cm}$ da altura do respaldo, para que se tornasse viável a adequação da altura mínima de 0,90m da base do espelho (Figura 14), conforme a NBR 9050/2015.

Figura 13 - Projeto executivo: Banheiro Acessível AutoClub Honda Campina Grande

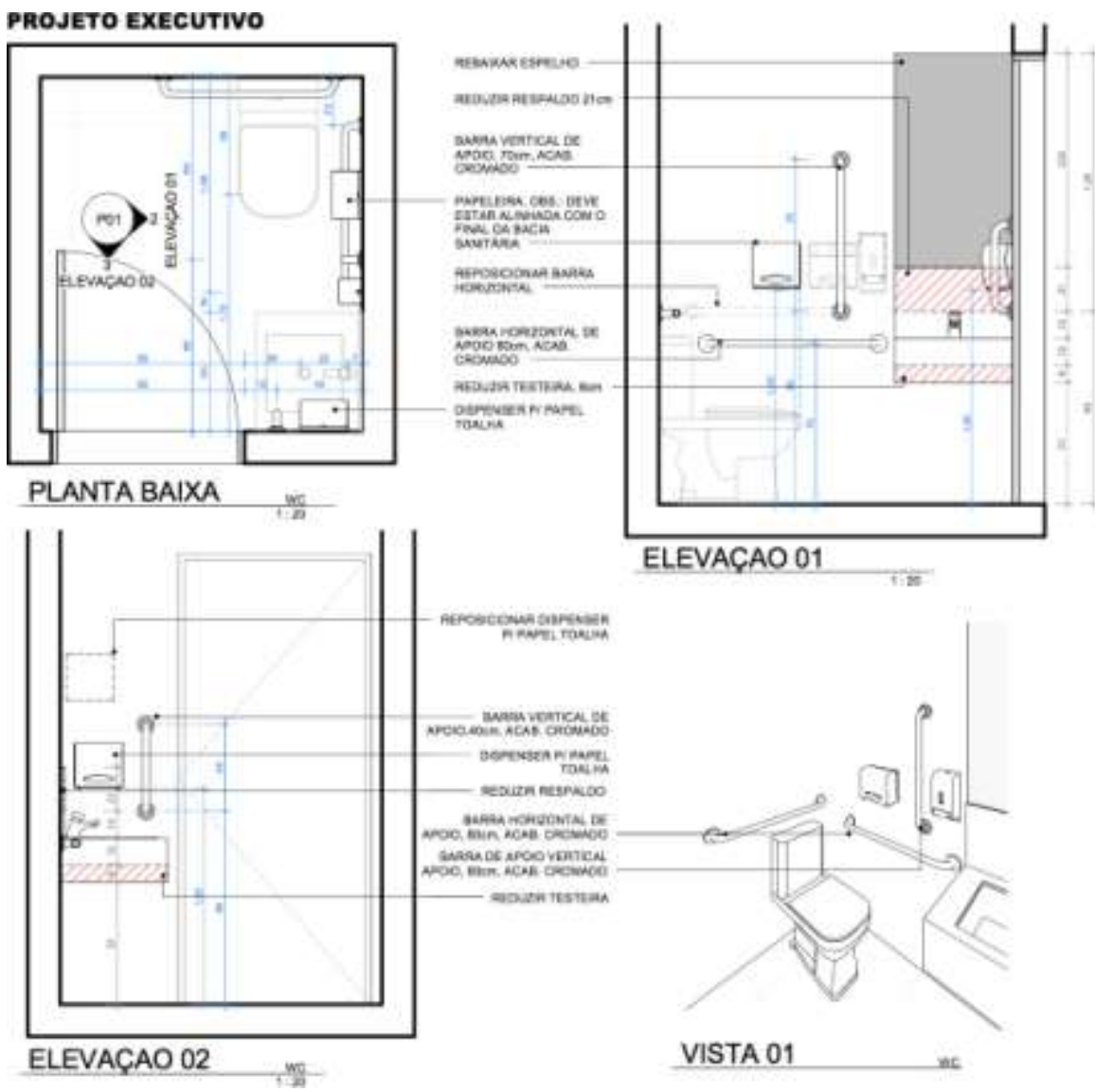

Fonte: LUCENA, 2017 


\section{(imase}

Figura 14 - Banheiro Acessível AutoClub Honda Campina Grande

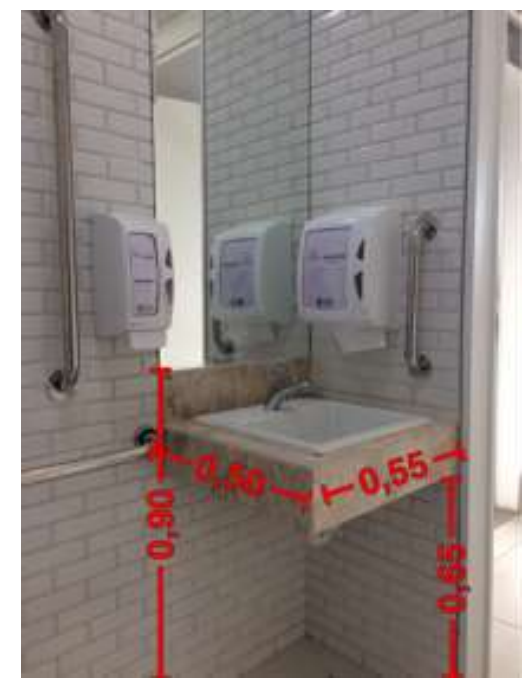

Fonte: Acervo pessoal, 2017

\section{CONCLUSÃO}

Uma vez que a acessibilidade passa a ser um tema mais presente e mais abordado nas empresas e dia-a-dia, a sociedade começa a ter uma nova visão sobre o assunto, mudando a realidade daqueles que necessitam de mudanças para viverem igualmente. A criação de normas que exigem um espaço adequado para que o portador de deficiência se sinta parte da sociedade, permitindo que ele transite e tenha sua independência, é um grande passo para essa mudança.

Cada ponto levantado foi estudado e avaliado em cada etapa para que se encontrasse a forma mais viável de realizar cada alteração de acordo com as recomendações da norma vigente. Mediante o exposto pode-se concluir que a AutoClub Honda BR 23, não cumpria em sua totalidade as exigências da NBR 9050 (2015) e o Decreto Federal no 5296/2004, necessitando assim de alterações com nível de adequação fácil (instalação de barras, adesivos, identificação visual, etc.) e com pequenas intervenções. As adaptações foram feitas seguindo as condições para a garantia do Certificado Honda Conduz, fundamentadas na NBR 9050/2015, para que tudo se tornasse adequado para o cliente portador de deficiência transitar e usufruir do espaço com autonomia, conforto e segurança.

\section{REFERÊNCIAS}

Associação Brasileira de Normas Técnicas. NBR 9050 - Acessibilidade e edificações, mobiliário, espaços e equipamentos urbanos. Rio de Janeiro, Maio 2015

BRASIL. Constituição (1988) Constituição da República Federativa do Brasil. 54 ed. São Paulo: Saraiva, 2017.

BRASIL. Lei no 13.146 de 6 jul. 2015. Institui a Lei Brasileira de Inclusão da Pessoa com Deficiência (Estatuto da Pessoa com Deficiência). Disponível em http://www.planalto.gov.br/ccivil_03/_ato2015- 2018/2015/lei//13146.htm. Acesso em 11 jan. 2018. 
CAMPINA GRANDE. Código de Obras do Município. Campina Grande, 2013

DISCHINGER, Marta. Promovendo acessibilidade espacial nos edifícios públicos: Programa de Acessibilidade às Pessoas com Deficiência ou Mobilidade Reduzida nas Edificações de Uso Público. Florianópolis : MPSC, 2012.

FARIA, M. D., SIQUEIRA, R. P., CARVALHO, J. L. F. S. Diversidade no varejo: Impactos de acessibilidade e inclusão na intenção de compra. Revista Brasileira de Marketing, $v$. 12, n. 3, p. 231-259, jul/set 2013.

FERREIRA, Mario dos Santos. Acessibilidade e Mobilidade Urbana: Planejamento e adaptação das cidades sob o enfoque da ergonomia. Revista da ADPPUCRS, v. n.9, p. 7883, 2008.

JOÃO PESSOA. Ofício Circular n 045/2016, 13 de janeiro de 2016. João Pessoa, 2016

KAUFMAN-SCARBOROUGH, C. Retailers" perceptions of the Americans with Disabilities Act: suggestions for low-cost, high impact accommodations for disabled shoppers. Journal of Consumer Marketing, v.15 n. 2, p.94-110, 1998

NETTO, Vinicius. O efeito da arquitetura: Impactos sociais, econômicos e ambientais de diferentes configurações de quarteirão.

<http://www.vitruvio.com.br/revistas/read/arquitextos/07.079/290>, Acesso em 13.02.18 as 15:30. 